\title{
History of the Study of Skeletal Muscle Function with Emphasis on Kinesiological Electromyography
}

\author{
Yves Blanc $^{*}, 1,2$ and Ugo Dimanico ${ }^{2}$
}

\author{
${ }^{I}$ Formerly In Charge of the Kinesiology Laboratory, Neuclid Department, University Hospital, 24 Rue Micheli du \\ Crest, 1211 Genève 14, Switzerland \\ ${ }^{2}$ Laboratorio Analisi del Cammino e del Movimento, S.S.D. Neurofisiologia Riabilitativa A.S.L. CN1, Osp. S.S. Trinità., \\ Fossano, CN, Italy
}

\begin{abstract}
Study of muscles started probably when someone tried to understand how he can move from A to B and executes movements at will. Knowledge was always dependent on the technology available to conduct investigation. Religious belief had a negative impact on muscle study when interfering with dissection of human corpse. During the Italian Renaissance (end of XIV th ${ }^{\text {th }}$ beginning of XVI th century), study of muscles was first descriptive, based on dissection. Artists like Leonardo da Vinci (1452-1519) and Michael Angelo (1475-1564) exaggerated the bulk of muscles. Their first concern was the influence of the volume of the superficial muscle on the surface modelling represented in their paintings and sculptures. Leonardo da Vinci multiplied the number of bundles of some muscles. Most of his representations of tendon insertions are imprecise. Leonardo da Vinci applied mechanical principles to rib, elbow kinematics and kinetics of the foot. Vesalius (1514-1574) was a medical doctor and an anatomist. His anatomical plates are remarkable because they respect most of the relationships between muscles. Then Galileo (1564-1642), Borelli (16081679 ) and Newton (1642-1727) thought that physics and mechanical laws governed motility of animal and human body alike. Incidental discovery of electro stimulation effect on muscle in Galvani's laboratory and electric current concomitant of muscles contraction by Matteucci and Du Bois Reymond were major breakthroughs. Recording of this current was the starting point for ECG, EMG and EEG. ECG entered first in the clinic. EMG and EEG waited for cathode ray oscilloscope.

The Voltaic Pile and faradic current opened the door of electrical stimulation to Duchenne de Boulogne (1806-1875).

Matteucci's (1811-1868) publications inspired and stimulated Du Bois Reymond. Du Bois Reymond (1818-1889) repeated and completed his experiments on frogs. He designed a very sensitive galvanometer with which he recorded his own global EMG. EMG remained a curiosity of laboratory until Erlander (1874- 1965) and his pupil Gasser (1888-1963) improved the cathode ray oscilloscope for electrophysiological recordings. A combination of orthopaedic surgeons, engineers and physiologists in Berkeley (1945) systematically recorded EMG during gait of normal man. EMG biofeedback and phonomyography have also raised interest by clinicians. Their EMG signals processing in the time domain (full wave rectification miscalled integrated EMG) was later completed in the early ' 80 s by computation of the root mean square on personal computers. Despite all factors minimizing the reliability of analysis based on amplitude of the EMG signals, these methods still represent the clinician's routine tool today. Since 1999, researchers have proven the benefits of muscular intensity analysis, time frequency analysis, mapping of spatio temporal activity. We deplore that the corresponding software is not available for clinicians. Multivariate methods of statistics allow the comparison of EMG patterns under pathological condition and can be helpful in differential diagnosis.
\end{abstract}

Keywords: Skeletal muscle, electromyography, kinesiology, history.

Egyptian fishermen feared painful shock generated by electric fishes like "torpedo marmorata Risso" of the Mediterranean Sea. Greeks and Romans used the electrical potentials delivered by electric fishes as therapeutic means. Electric organs are modified muscles cells or branched nerves endings that generate electric fields. These fishes where probably the first recorded manifestation of electricity produced by muscles. The practice of using electricity for pain control can be traced to 2500 BC and the Egyptian Fifth Dynasty, in which stone carvings depict an electric fish being used to treat pain. During the Socratic era,

*Address correspondence to this author at the Route de Frontenex 43, 1207, Switzerland; Tel: 412273522 21; E-mail: yv-blanc@bluewin.ch electrogenic torpedo fish (Scribonius longus) were used to treat arthritis and headache. [1] This scope of application is the ancestor of Trans Electrical Neuro Stimulation (TENS). Electromyography (EMG) biofeedback [2-4] and myocontrol of prosthesis are other clinical applications of the current produced by muscles.

"WHY" and "HOW" drive human movement. Psychological aspects of the movements depend on the "WHY" and "WHEN" while "HOW" relates to motor patterns, muscle mechanic and sensory control.

Study of function and action of skeletal muscles has been dependent upon technology available to researchers and clinicians. Philosophical or religious interdicts have limited access to knowledge through dissection of corpses. 
Successive eras of investigation starting with dead muscles have come to the use of dynamic poly electromyography of living subjects during their recreational and usual activities.

\section{ANATOMICAL ERA: TIME OF "WHAT MUSCLES MIGHT OR CAN DO!"}

In ancient Greece, based on dissection of human corpses, Herophilus of Chalcedon's treatises (ca. 300 BC) (are lost but were reported by Galenus) and his pupil Erasistrus of Chios (ca.304-ca.250 BC) were interested by the brain and organs but not by muscles. Myological studies described muscles origin and insertion, based on observation and geometrical analysis; from his observations, Aristotle (384$322 \mathrm{BC}$ ) deduced the potential action of various muscles [5]. His treatise "De Motu Animalium" described the actions of muscles with geometrical analysis. Later Borelli called also his treatise "De Motu Animalium " (1680). In the pagan Roman Empire, political authorities prohibited dissection of human corpse so Claudius Galenus (Claude Galien, Galen) (AD 131-201), Greek physician, anatomist and physiologist, dissected primates and transposed his knowledge to human anatomy. This extrapolation was not without consequences on the development of anatomy and surgery. His medical influence remained predominant for about 1500 years until the Italian Renaissance. He thought that "animals spirits" controlled muscular contraction [6] As the physician of a team of gladiators; he probably acquired a great knowledge of functional anatomy and traumatology. Even if he wrongly assumed that primates and human beings share the same anatomy, his work remained the reference among physicians until Ambroise Paré (1510-1590) and Vesalius (1514-1564).

From $10^{\text {th }}$ to $12^{\text {th }}$ centuries Arab physicians installed in Spain boomed in surgery and design of surgical instruments. Human dissection supported their anatomical knowledge but study of muscles function seems out of their field of interest. Our anatomical nomenclature suggests that Greeks and Romans physicians were prominent but authors of the Renaissance period translated their name in Latin Arabic names still used actually.

It seems that Galenus remained the reference in anatomy until Vesalius (1514-1564) published "De humanis corporis fabrica" and his" Epitome" in 1543. Christian theology did not prescribe human dissection and autopsy universally. Michelangelo's patron Popes Sixte IV (1471-1484), then Clement VII (1523-1534) permitted human dissection [7]. Human dissection and autopsy was a physicians' privilege. Meanwhile, painters and/or sculptors attended physicians' teaching and managed to dissect, more or less secretly, unclaimed corpses of vagrants or executed convicts. With Prior Nicolas Bichiellini's agreement [7] Michelangelo ((Michelangelo di Lodovico Buonarroti Simoni (14751564)) studied anatomy through dissection in hospital Santo Spirito in Florence. Nevertheless, like many contemporary artists Michelangelo was not interested in the function of muscles but in their shape, bulk, relationships and proportions in various postures.

Painter, anatomist and engineer among many other talents, Leonardo da Vinci ((Leonardo di ser Piero da Vinci (B. April 15, 1442; D. May 02. 1519)) is may be the first to apply mechanical thinking to human posture. His anatomical sketches are imprecise and unreliable in term of origin and insertion of muscles i.e.: sketches of a man posterior view of the arm, shoulder, and trunk. After the removal of the skin: the bulk of middle trapezius, posterior deltoideus, brachio radialis are exaggerated while lower part of trapezius and latissimus dorsi are curtailed to emphasize the volume of para spinalis muscles. Leonardo da Vinci used letters to name anatomical pieces. He exaggerated the bulk of the muscle and areas of insertion are imprecise. [8]. These drawings are useful for painters and sculptors alike. They outrageously emphasised the bulk of muscles and does not respect the ratio of volume between muscles. In his mechanical sketches, muscle bundles are represented by cords or muscle equivalent materializing their direction of pull. He replaced a muscle by its "muscle equivalent" or cord without considering that some tendons wraps up around joints and/or bones which modifies the direction of their force of pull and the intensity of their peripheral and radial forces. Actually, some software still uses the same concept reproducing the same errors. Weight, pulley and string replaced also traction of muscles. Influence of the length of the muscle lever arm on the range of motion was sketched comparing monkey and man arm. His kinematic drawings emphasized the effect of the point of muscular insertion on the range of motion and force. This observation corresponds to "shunt" and "spurt" muscles defined by Mac Conaill \& Basmajian, 1969 [9]. From his architectural sketches of simple device to lift heavy weight, he derived lever to describe the action of the calf when rising on tiptoe.

Andries van Wesel (1514 - 1564) known as André Vesale, Vesalius or Andreas Vesalius, was a physician and anatomist. Born in Brussel he had the Spanish citizenship. Some historians of medicine think he was the greatest anatomist of the Renaissance. The precision of his descriptions combined with the detailed illustrations of the plates engraved by Jan Van Calar a Tiziano one of Vecellio's pupils, "De humani corporis fabrica libri septem" published in 1543 in Basileae (Basel) by Ioanis Oporini are striking of realism. The same editor published a version for students "De humani corporis fabrica librorum epitome" the same year. A fac simile of his illustrations is available with comments and translation by Saunders and O'Malley [10]. It is interesting to notice he presented dissected corpses in "live posture". Our contemporary anatomist, famous for his technique of plastination, Gunther von Hagens also presents corpses in "live posture and recreational activities".

We do not know if muscle function and mechanic interested Vesalius or if he limited himself to descriptive anatomy and teaching. Vesalius ended Galenus's leadership on anatomists.

Galileo Galilei (1564 - 1642) mathematician and scientist is mainly known as an astronomer. Muscle did not particularly interested him but he searched for the laws governing motions. His experiments on falling objects demonstrated that the relationships between space, time and velocity is crucial in mechanic of motion.

His pupil Giovanni Alfonso Borelli (1608 - 1679), professor of mathematic in Messina (Sicily) then at the University of Pisa (Italy), physiologist and physicist, accessorily anatomist and astronomer, carried on the same path. He followed Galileo's principle of scientific investigation and applied mechanic to solve animal and 
human's muscular movement. "His theory was that bones are levers and that muscles function according to mathematical principles" [11, 12]. However to explain muscular contraction he repeated more or less Aristotle's theory " nerves are canals filled with a spongy material through which flow animal spirits (succus nerveus), sometimes translated "nerve gas"; that agitation of these spirits from the periphery to the brain produces filling and enlargement of the porosities of the muscles, with resultant turgescence. Reaction of these spirits with a substance in the muscles themselves initiated a process resembling fermentation, with subsequent contraction. He distinguished between tonic and voluntary contraction and perhaps vaguely perceived the principle of reciprocal innervation and antagonistic muscles" [13]

His work on movement of animals and humans "De motu animalium" volume 1 and 2 were published post mortem in 1680 and 1681. These two volumes are considered like the first treatises of biomechanics. Following Descartes and influenced by Harvey's mathematical explanations of the blood circulation, he founded the iatrophysical school which members though that the laws of physic explain all physiologic and pathologic phenomena. However, Francis Glisson (1597 - 1677) disputed his theory of muscular contraction. By plethysmographic experiments, he demonstrated that muscles contract and not expand. "He suggested also that all viable tissue possesses that capacity to react to stimuli. This capacity is referred as "irritability". Glisson's concept was later elaborated by Albrecht von Haller (1708 - 1777), the outstanding physiologist of the Eighteenth century, into his theory that contractility is an innate property of muscle which exists independently of nervous influence" [14]. Irritability of muscular fibre refers to the contraction of the muscular fibre under excitation. Somehow, Galvani's assistant incidental contraction of the muscles of a leg of a frog during a storm in Bologna (Italy) in 1786, confirmed Glisson's theory.

To identify muscles Galenus used number, Leonardo da Vinci and Vesalius used letters. Muscles received Latin names in the $18^{\text {th }}$ century.

John Hunter (1728 - 1793) anatomist and surgeon delivered six Croonian lectures on Muscles Motion from 1776 to 1782 . He reported his "observations concerning the structure and power of muscles and the stimuli by which they are excited...... He emphasised that muscular function can be studied only by observations of living persons, not cadavers" [14].

\section{ERA OF ELECTRICAL STIMULATION: PHYSIO- LOGICAL STUDIES}

This era started when incidentally, in 1786, one of Galvani's assistant touched a nerve of a frog leg with a metallic rod charged with static electricity. He observed a muscular contraction. Luigi Galvani (1747 - 1798) physician, obstetrician, physiologist and anatomist opened a new area of muscular experimentation and research. "Galvani wrote, "While one of those who were assisting me touched lightly, and by chance, the point of his scalpel to the internal crural nerves of the frog, suddenly all the muscles of its limbs were seen to be so contracted that they seemed to have fallen into tonic convulsions" [15]. He named this phenomenon "animal electricity" also called "animal electric fluid ". For his ulterior experiments, he used a Leyden jar, which is an accumulator of static electricity. He published his experiments in "De viribus electricitatis in motu musculari commentarius" in the $7^{\text {th }}$ volume of the memoirs of the Institute of Sciences at Bologna in 1791." [16]. For some times Galvani's animal electric fluid replaced Aristotle and Borelli's nerve gas generated by the brain and propagating along the nerves to the muscles.

Thrilled by Galvani's experiments Alessandro Giuseppe Antonio Anastasio Volta, physicist, interested in chemistry and physiology, (1745 - 1827) invented the term "galvanism". However, he refuted Galvani's interpretation of "animal electric fluid"; this led to a fierce controversy between static electricity and dynamic electricity.

Volta demonstrated that two different metals in contact with a frog nerve or muscle generated a current, which provoked a muscular contraction. He concluded that different metals are the "motor" of electricity and frogs are simple but sensitive detectors of electricity. In 1800, he presented "an artificial electric organ". This new electrical generator was named the "Voltaic Pile". The Voltaic Pile delivered a DC current of low intensity. This settled, for a time, the controversy with Galvani's theory of animal electricity [17]. Following Volta and Galvani, Carlo Matteucci $(1811$ - 1868) showed that electricity produced by the evoked contraction of a muscle of one frog (A) can be transmitted along the motor nerve to a second frog (B). This electrical stimulus was powerful enough to trigger a contraction of the muscle of the second frog (B). Galvani and Volta discoveries had no or little impact on medical sciences until reliable stimulators delivering accurately controlled current were available see [18].

Michael Faraday, physicist and chemist (1791 - 1867) [18] designed devices, which produce alternative current named faradic current [19]. This current induces muscles contraction when applied to the nerve or to the muscle through the skin. Nowadays, it is widely used in therapeutic electro stimulation even if there is a persistent lack of evidence of its usefulness in prevention of atrophy in peripheral and central paralysis and paresis.

Guillaume-Benjamin Amand Duchenne (nicknamed Duchenne de Boulogne) French physician, neurologist (1806 - 1875) extensively used localised faradisation to " determine the proper action which the muscles possess in life, their mechanism, as direct voluntary motors, or moderators, or synergistic factors to prevent abnormal motion, and finally, as forces which contribute to then normal position of extremities during muscular rest by the tension of their tonic tension.

The possibility of limiting the electric stimulation to each muscle or separate fibers, and thus imitate voluntary muscle contractions would give a fair idea of the individual action of the muscle and, generally, of the physiology of motion of the living man. This method of electric stimulation was similar to the study of anatomy on living animal as practised by the old anatomists, and permitted for the first time to experiment on the living man without an operation, using a harmless process of my localised faradization." [20] We have not retrieved the characteristics of the current he used. He 
demonstrated that faradisation of the Extensor Digitorum Longus brings the foot in slight dorsi flexion and mainly in supination. He showed and underlined the fact that the Tibialis Anterior alone cannot dorsiflex the foot. Its faradisation supines the forefoot with a mild dorsiflexion. The simultaneous toe flexion is due to the passive stretching of the flexors hallucis longus and flexor digitorum longus. Full dorsi flexion is achieved only if Tibialis Anterior and Extensor Digitorum Longus have a balanced and simultaneous contraction. Predominance of pull of Tibialis Anterior over Extensor Digitorum Longus creates the typical supinated foot deformity i.e. seen in stroke, varus equinus club foot. A SPLATT procedure rebalances the foot [21]. A burst of EMG activity of the tibialis anterior at the transition stance to swing is a prerequisite for an efficient SPLATT, which corrects the forefoot supination, possibly the rear foot varus and reduces the foot drag.

If the EMG burst is delayed from the start and / or during the early swing phase, the forefoot deformity is controlled but clearance problem will persist. In this situation, the SPLATT has mainly a tenodesis effect.

Duchenne de Boulogne's published in 1862 his pioneering work on expression provoked by faradisation of facial muscles "Mécanisme de la physionomie humaine ou analyse électro-physiologique de ses différents modes d'expression" Paris Asselin 1862 (reprinted in 1876 then translated in English in 1990 [22]. He thought that soul controls facial muscles to express our emotions and sentiments. The photographs taken of the facial expressions during his expriments are striking. While the subject lowered voluntarily his mandible, simultaneous stimulation of both musculus corrugator superficili and musculus cutaneus colli produces an expression of terror and pain. The expression of fear was not a painful reaction to the stimulus because the patient had a hypoesthesia to pain and was not experiencing pain. Selective stimulation of the musculus zygomaticus major elicits the expression of joy. Duchenne de Boulogne called zygomatus the muscle of joy. So far, we have not found any study confirming Duchenne's systematic work.

\section{ENGINEER'S ERA: TIME OF “WHAT MUSCLES SHOULD DO"}

In 1874, Pierre Jules César Jansen (1824 - 1907), astronomer, commissioned the making of a photographic device named "revolver photographique" to photograph the phase of Venus passing in front of the sun [23]. It takes frame-by-frame photographs at fixed intervals. Frame by frame photos split movements and trajectories into their sequences and phases. Development of sequential photography of a galloping horse (1877) by Edward James Muybridge (1830 - 1904) popularised extensive studies of kinematics of functional activities of human and animals. Engineers and physiologists developed special instruments and methods to study heart, muscles, gait, flight of birds and insects [24, 25].

Marey recorded changes of the volume of muscles of the chest during the flight of pigeons. He used the same technology to record heart rate and human myograms. The pigeon wore a tight waistcoat holding a manometer in front of the pectoralis muscles. Variations of volume of the chest modify the pressure on the manometer. A very soft tube of rubber transmitted these variations of pressure to the fixed or portable recording unit.

Marey and Carlet applied a scientific method to extensively study human gait during the second half of the nineteenth century. Jules Etienne Marey (1830 - 1904) physician, physiologist developed a sphygmanometer to study the physiology and patho-physiology of heart. Later he focused his work on kinematics and movement decomposition based on chronophotography (high speed photography). He probably modified Janssen's "revolver photographique" for his recordings of kinematics. He developed a complete set of equipment and techniques and adapted photography to Lippmann's electrometer (1877) to display electrical activity of the heart of turtle and frog but we have not retrieve any recording of electrical activity during muscular contraction [26]

His colleague Gaston Carlet recorded sequence of contraction of muscles, called myogram, with the sphygmanometer that Marey [cf. 22] developed to record pulse of human beings and flight of pigeons [27]. Now we know that these myograms give false timing of the muscular sequences. Later with a less precise method for the muscle ON-OFF timing but improved for the foot rollover, Scherb reproduced the same error while palpating the muscle belly and tendons of subjects walking on a treadmill. Sphygmanometer and palpation records globally changes of the firmness of the under lying tissues. Firmness varies during muscular contraction but also if muscles are stretched or passively shortened. Electromyography has demonstrated that myographs are unreliable. Incidentally, Marey's stance and swing were false because his pressure sensors included in the sole of a shoe did not touch the posterior and anterior borders of the sole. Actually, the same error perpetuates if one uses 3 foot switches (under heel and metatarsal heads) to record foot rollover, stance and swing phases duration.

A special mention is due to Isaac Newton $(1642-1727)$, mathematician and physicist. His formulation of the three laws of movement and rest is a milestone in modern kinesiology. They are relevant in kinetics and sports. The parallelogram of force applied to muscles splits up the muscular force (resultant force) into its radial and peripheral components [28].

Adolf Eugene Fick (1829 - 1901) mathematician then physician ophthalmologist and physiologist, inventor of the contact lens, was also interested by muscular movement and its energetic. He introduced the terms "isometric contraction" and "isotonic contraction" [29].

According to Rash, in 1897 experimenting on dogs walking and running on a treadmill, Morburgo wrote "As certain as is the fact that the mass of voluntary muscles increases in response to greater work so uncertain is our knowledge concerning the mechanism that underlies that enlargement. There is no lack of assertion in the literature that deal with this subject in more or less decisive fashion and interpret the activity-hypertrophy as either a true hypertrophy in the sense of Virchow or as a combination of hyperplasia and hypertrophy; but exhaustive proof is everywhere lacking" $[30,31]$. See also Siebert [32]. Wilhelm Roux (1850 - 1924) "muscular hypertrophy develops only after a muscle is forced to work intensively" (we have not retrieved the 
original of this statement). Among other physiatrists, in 1952 Delorme codified a method for muscle strengthening [33, 34].

Jules Amar (1879-1935) engineer, physiologist, ergonomist, considered the couple muscles-bones as a motor powered with food. He applied mechanical rules, parallelogram of forces and similitude between man and machine. He referred to Galileo, Newton and Marey among others. He used ergometers but we have not found any reference to EMG [35]. Amar published also a book on the physiology of industrial organisation and the re-employment of the disabled. He used Marey's and Carlet's devices to measure muscular activities [36]. He paid a special attention to power and mobility of stumps from First World War amputees.

Muscle modelling is widely used in simulations that compute the potential role of muscles in controlling posture and movements like gait or sport activities. Researchers favour Hill based models. Usually common Hill models assume that force-velocity; length-tension and activation properties are independent. Errors of a common Hill model are greatest between $10-20 \mathrm{~Hz}$ and depend on how the model activates the muscle(s). The most prevalent error is the inability to account for, at low motor unit firing rate, the coupling between force velocities properties and muscle activation [37]. Clinicians must be cautious when interpreting results of computation of muscle force and muscle length. They must first understand the limitations and pitfalls of the model.

\section{PIONEERS IN ELECTRO PHYSIOLOGY, PRECUR- SORS OF ELECTROMYOGRAPHY}

After Galvani and Volta, Carlo Matteucci (1811 - 1868), Italian mathematician and physicist, repeated and improved Galvani's experiments. He demonstrated that electricity produced by muscle contraction of one frog could induce contraction of a muscle of another frog (c.f. figure 12 [38]). However, he did not interpret his results, his professor and friend Antoine César Becquerel (1788 - 1878) proposed the correct interpretation of Galvani's experiments on frogs. Initially he measured bioelectricity with Nobili's astatic galvanometer developed in 1825 . Then in 1846 , he invented a "kymographe" which recorded and measured electricity produced during muscular contractions over time. This might be the first recording of electromyography from animals even if anteriority is often attributed to Du Bois Reymond around 1849 . His results in bioelectricity strongly influenced $\mathrm{Du}$ Bois Reymond. Finally, in 1848, he withdrew from sciences to politic and became an influent member of the "Risorgimento" (Italian unification) after the Italian revolution of 1848 .

Emil Heinrich Du Bois Reymond (1818 - 1896) was a German mathematician and professor of physiology. From 1841, he repeated, verified and extended Matteucci's work on the electrical properties of frog muscles i.e.: Essai sur les Phénomènes électriques des Animaux published in 1840 . He studied electricity generation of electric fishes and conduction along nerve. He discovered the nerve action potential. In 1849, an academic controversy about the discovery of electric current produced by muscular contraction opposed him to Matteucci [39-42]. In 1849, he invented a very sensitive galvanometer then showed the first representation of the electrical activity concomitant of muscular contraction in human: probably the first representation of EMG signals. We have not retrieve any printout of his first EMG recording. May be sketches in his notes in his laboratory dairy $1845-1849$ represents this EMG.

Einthoven Willem $(1860$ - 1927) physician continued Waller's pioneering work of electrocardiography. To improve the quality of the recorded ECG signals he boosted the improvement of the capillary electrometer. The quality of the ECG signals allowed the comparison of normal and pathological subjects. For his work on ECG recording and interpretation Einthoven received the Nobel Prize of Medicine in 1924. Later his technological improvements benefited to electromyographers.

Both Einthoven and Du Bois Reymond used large electrodes that mean extremely poor selectivity and consequently no specificity of the signals. Einthoven detected ECG with three electrodes: each hand plunged into a bucket of water and his left foot into a tub. His recording with a capillary electrometer reminds Marey's photos of the ECG of turtles and frogs. Then, since 1903, his string galvanometer recorded ECGs with their actual aspects.

From his photo, Du Bois Reymond recorded a sum of currents with two electrodes, between his right hand plunged into a jar filled with a conductive liquid (water ? salted water?) and his left hand holding a metallic bar. His recording device was most likely his capillary electrometer which displays the variation of current between the two electrodes but did not stored the signals. From a drawing explaining his photo, arrow indicates the direction of the current from his right hand to his left hand across his chest. The recorded electrical potentials are the algebraic sum of all the muscles active between both hands. Du Bois Reymond's first recording were monopolar no third electrode (reference or ground electrode) is visible. This method cannot localise the origin of the source of the EMG signals. Its lack of specificity and accuracy represents its main drawback. It is not reliable for kinesiology. Another milestone of EMG was the recording of the so-called "Piper rhythm" 1907 [43]. The electromyogram (EMG) of healthy humans demonstrates a tendency to rhythmically oscillate at around $40-50 \mathrm{~Hz}$ (range 30-60) $\mathrm{Hz}$ (the Piper rhythm). It increases from weak to strong voluntary contraction [44].

Available technology limited their recording possibilities. The modern era of electro physiology started in 1922 when Joseph Erlander and Herbert Gasser modified a cathode-ray oscilloscope and recorded nerve action potential $[45,46]$. They won the Nobel Prize of Medicine in 1944. Nowadays electrode size and selectivity remains a major issue for accuracy and reliability of surface EMGs.

Adrian gave some advices to record surface EMG but unfortunately, was not interested by selectivity of surface electrodes. The base line of his figures is very thick; we suspect that significant amplitude of noise polluted his data. Noise (50 $\mathrm{Hz}$, white noise) was common fact before bipolar detection and low noise differential amplifier [47, 48]. In 1929, Adrian and Bronk designed and developed their concentric needle electrode to pick up motor action potentials (MUAPS) from small number of motor units within deep muscles. They gave access to small 
volume of muscular tissue and to deep muscles. For diagnostic neuro electromyography, physicians still use these electrodes. However, these stiff electrodes are unsuitable for kinesiological EMGs.

\section{KINESIOLOGICAL ELECTROMYOGRAPHY (EMG) GIVES THE ANSWER TO "WHEN" AND "WHICH" MUSCLES OR "PART OF A MUSCLE" ARE ACTIVE IF THE DETECTING ELECTRODES GUARANTEE THE SPECIFICITY OF THE EMG SIGNALS}

During his Croonian lecture Beevor [49] questioned: "Which is the best method to ascertain the action of a muscle?" He listed "three chief methods":

1. the anatomical method, which is employed on the dead subjects and consist in dissecting out a muscle, freeing it from its connexion, but leaving it attached at its origin and insertion. The muscle is then pulled up by the dissector and the resultant position of the limb is taken to show the action would exercise during life.

2. the electrical method. Duchenne employed it.

3. the physiological or natural method, differs from the first two in reversing the order of procedure .... in the physiological method a living person is told to perform a definite movement and it is then observed which muscles take part in this movement. ... The mean that I have used for determining whether a muscle is taking part in any given movement are inspection and palpation either of the muscle as a whole of its tendon."

Beevor palpated muscles and/or tendons in -1- free movements, -2- against a load, -3-of limb fixed by an opposing force. Despite its lack of specificity, reliability and accuracy, this method is still widely used by clinicians and physical therapists alike during manual muscle testing. No doubt, that if the EMG had been available Beevor would have used it to analyse the sequential muscle ON-OFF patterns during free movements.

Scherb Richard, (1880 - 1955) [50, 51] orthopaedist, repeated the same method and the same errors to study muscular patterns when a subject walked on a treadmill. Three ON-OFF switches, under heel, fifth and first metatarsal areas detected partial sequences of each foot roll over.. He combined five errors: -1 -footswitch too forward under the heel-2- no footswitch under the great toe -3combination of 1 and 2 give false stance and swing duration, -4- no specificity of EMG electrodes because they are too far apart -4- walking on a treadmill, which is different from normal gait and -5-palpation that does not reveal the true pattern of a muscle.

Unlike ECG, kinesiological EMG remained confidential in physiology laboratories until technological breakthroughs simplified recording procedures and allow testing during dynamic situations. Movement analysis benefited and sprouted when poly channels recorders become available. At first researchers recorded kinesiological EMG on ECG or EEG strip chart recorders because they offered many channels. However, their low bandwidth filtered the high frequency components of any EMG signal: minimizing its amplitude and impoverishing its frequency content. They modify EMGs like a low pass filter. Another weak point was the contamination by $50 \mathrm{~Hz}$ combined with movement artefacts of high voltage.

Few anatomists used kinesiological EMG to investigate muscle sequences during free movements. John V. Basmajian (1921 - 2008) anatomist, physician with interest in rehabilitation and biofeedback, is often considered as the father of kinesiological EMG. In the preface of the second edition, 1967, of "Muscles alive. Their functions revealed by electromyography" Basmajian wrote "The place of Electromyography in biology and medicine. A brief review of the special role that electromyography has assumed in scientific research is a proper ending for this introductory chapter. As with other scientific techniques, this one arose in response to a need. Obviously, the actions and functions of muscle had not been fully understood in spite of continued interest and investigation. Not withstanding the admirable zeal of many investigators, serious limitations in the classical methods of muscle-evaluation account for the gaps and errors in our knowledge.

The classical methods of study on which most of our knowledge of muscle function have been based are: (1) topographical study of dead muscles combined with mechanistic calculations of what they "ought to do", (2) direct electrical stimulation, (3) visual observation and palpation through the skin of the muscles in action and (4) study of paralyzed patients and an evaluation of the deficits.

Except in some obvious applications, the above methods are incomplete, whether they are taken alone or all together. They cannot adequately reveal - as electromyography can the function of deep, impalpable muscles and the exact timesequences of activity. It is not enough to estimate by classical methods what a muscle can do or might do. Electromyography is unique in revealing what a muscle actually does at any moment during various movements and postures. Moreover, it reveals objectively the fine interplay or coordination of muscles; this is patently impossible by any other means" [52] Basmajian compiled publications reporting muscles activities and interplay under voluntary controlled or free movement. He regularly upgraded them until the last fifth edition in 1985.

Surface EMG (sEMG) senses only muscles under the skin. Deeper muscles are only accessible with indwelling electrodes. Rigid (Rhen, 1921) and coaxial needle electrodes (Adrian, Bronk, 1929) used in clinical EMG are inappropriate in kinesiological EMG because they generate pain and artefacts during movement. Pain and fear of pain modify the subject's behaviour and consequently the pattern of movement or posture. Bi-polar fine wire electrodes (Basmajian and Stecko, 1961) are the best compromise when we examine deep muscles and / or very slender muscles [53]. Accurate localisation of the tip of each wire within the targeted muscle must be controlled by electrical stimulation at the beginning and end of each recording session. Beware that fine wire recording are not free of crosstalk.

The huge number of American veteran amputees during World War II brought a need to develop better, more comfortable and reliable prosthesis. For that purpose, a thorough study of normal gait was organised. Instrumental gait analyses, kinematics, kinetics and EMG started in 1945, 
led by orthopaedic surgeons, had its cradle in the departments of civil engineering and orthopaedic surgery of the Berkeley school of medicine at the University of California, in San Francisco [54, 55]. It was the first comprehensive study of gait that reported kinematics and EMG patterns of lower extremity of normal adult men. Results were widely spread in the medical community [56]. Raw EMG signals was rectified and low pass filtered to produce smooth rectified EMG. Polarity of one group of muscles was reversed to easily correlate timing with its antagonistic group i.e. pre tibial and calf groups. Psychologists then favoured this presentation because comparison of timing between two channels is easier at a glance. Precise relationships of phase timing were established on filtered EMG. Overlay of smooth rectified EMG from various gait cycles normalised over time showed the between cycles variations of EMG amplitude and timing of peaks. Then these normalised full wave rectified EMG were averaged to show a "typical pattern". What they named integration (integrated EMG) is not a true mathematical integration of the signals but a smoothed rectification.

Verne Thomas Inmann (1905 - 1980) anatomist and orthopaedic surgeon transmitted his passion and belief in the usefulness of EMG to study gait, patients' follow up and help in decision-making. Amongst many others, his most famous pupils are (in alphabetic order): John V. Basmajian, J.R. Close, Jacquelin Perry and David Sutherland. Nowadays, the least remembered is probably Dr. J.R. Close (1913 - 1980 ?). His books [57, 58] should be on a list of "must be read" by those interested in tendons transfer and kinesiological EMG of hand and leg. With the help of EMG, he showed that a muscle rarely changes its phasic activity after a transfer of one of its tendon. He referred to more than 125 patients for the lower extremity and 150 for the hand, mainly polio: "despite its ability to voluntarily perform the function for which they are intended is well known.... For instance, the peroneus longus transferred to the dorsum of the foot may act as an excellent voluntary dorsiflexor. The same muscle may fell completely to act during the swing phase of walking when its action is required to dorsi flex the foot and prevent a foot drop. This change in the muscle's phasic activity is maintained only as long as the patient concentrates on its use" "Thus the demonstration of the voluntary action of a transferred muscle with the patient sitting may have nothing to do with the effectiveness of the transfer during walking." Same observation applies to upper extremity especially at the upper extremity during reaching, handling and object manipulation. Before soft tissue surgery (lengthening, release, tendon transfer), a functional EMG is of great value to select the most appropriate candidate with the corresponding phasic pattern $[57,58]$. We made the same observation in patients with upper motor neurone lesion i.e. cerebral palsy, stroke, incomplete spinal cord lesion and multiple sclerosis.

Cineplastic surgery of muscle(s) from the stump of the arm of an amputee to power hand prosthesis was disappointing because, when under permanent passive tension, muscles adapt their length and loses their power to animate the prosthesis [59].

\section{KINESIOLOGICAL EMG SINCE THE ADVENT OF COMPUTER}

EMG became largely involved in ergonomics when calculators and later computers become easily available for measurement of localised muscular fatigue. One breakthrough was the possibility to compute, fast Fourier Transform (FFT) and extract power spectrum of the EMG signals on home PC [60-65].

Digital transmission and storage of EMG data have replaced strip chart recorders and FM tape to store signals. Unknown new problems and artefacts have replaced known ones. Processing of signals either in time or frequency domains is faster. Automatic recognition of ON-OFF patterns is still unsatisfactory, is it too dependent of the signal to noise ratio. Programmers must improve ergonomics of software to make it user's friendly and time saviour tools in a clinical setting. We are still waiting for indexes and/or criteria to estimate the probability of cross-talk versus cocontraction in sEMG between channels and/or adjacent muscles [66].

Advanced signal processing has not entered clinical practice. Raw filtered EMG remains the golden standard to read muscular patterns. Processing and statistics are useful to compare within and between trials and subjects after normalization of data. Since 1999, Von Tscharner and col. [67], have proven the benefits of surface EMG intensity analysis, time frequency analysis, They computed the energy contained into the SEMG signals based on its frequency contents over time and not only its amplitude variation [68]. Overall, amplitude variations alone are contingent upon external factors attenuating muscular action potentials amplitude. Using sEMG to map of spatio temporal activity at the spinal cord level is also interesting [69-72]. This mapping relies on published distribution of motor nerve roots and spinal muscular nuclei (myotomes) of each muscle. Clinicians use these tables to estimate the level of the spinal cord lesion after a spine injury. We can imagine that the process be extended to Penfield's motor homunculus and its refinement from MRI maps. We deplore that the corresponding software is not available for clinicians.

Multivariate methods of statistics allow the comparison of EMG patterns under pathological condition and can be helpful in differential diagnosis [73]. Arrays of electrodes allow localisation of innervation zone(s) of superficial muscles at the surface of the skin. They are not adapted for daily movement analyses. They are potentially interesting for those injecting botulinum toxin and to follow progresses of re-innervation.

Despite technological improvements, the main enemies of EMG are -1- too easy to get EMG signals even with inappropriate equipment and conditions, -2- especially without selective electrodes -3- without any knowledge of functional anatomy, -4- over interpretation of signals that leads to misinterpretation.

Does kinesiological EMG decline in gait analysis laboratories? Since the 80 s, when $3 \mathrm{D}$ gait analysis based on video became affordable and fashionable, mechanical engineers and bio-engineers in charge of gait laboratories 
have favoured kinetics (net joint moment and net joint power) to consider muscle behaviour. This is an unwise decision. Net joint moment and net joint power do not give information about the behaviour and timing of the moment and power of antagonist muscles. Assumption that net joint moment depicts the timing and the EMG pattern of the dominant muscular group has never been confirmed in our experience consequently kinetics cannot replace kinesiological EMG. Some gait lab engineers forsake and/or scorn kinesiological EMGs probably because recording EMG is too time consuming and needs an extreme rigour. Furthermore, EMG is unsuitable to compute muscular forces accurately.

\section{EMG BIOFEEDBACK}

The ability to voluntarily modify the firing rate of a single motor unit in the ' 60 s opened a field of clinical research in the treatment of stroke [74]. In the early 1970, Basmajian presented EMG biofeedback as a tool enabling patients to acquire or reacquire a better voluntary control of their skeletal muscles [75]. A line of surface EMG apparatus was specially developed: visual feedback of the raw EMG with or without auditory feedback. Selectivity of electrodes and electrode placed on "minimal crosstalk areas" condition the fidelity and the specificity of the sEMG signals [76]. Recognition of crosstalk versus co-activation is still a matter of personal expertise because we do not know any reliable index or coefficient that estimate them automatically. Main goals of muscular biofeedback were to improve the contraction of weak muscles and to reduce activity of socalled "spastic muscles". Psychotherapists used it to enhance and speed up patients' relaxation. A change of ability to regain motor control under visual and auditory feedback is easy and quick. However, the integration of this change (post effect) with deprivation of external feedback is not accessible to every one. Integration of proprioceptive and other sensory information is impossible if the subject has lost his or her capacity of abstraction. Since the mid ' 80 s, EMG biofeedback has steadily lost its interest because of the limited long-term results. In addition, its interference in the relationship therapist-patient bothered some therapists jealous of their power.

PHONOMYOGRAPHY is the recording with a microphone placed on the skin over a contracting muscle of the sounds concomitant of muscular contraction. In 1866, Marey wrote that in $1809 \mathrm{Dr}$ Wollaston reported that a muscle in a tetanic contraction vibrates and generates an audible noise at $32 \mathrm{~Hz}$ [77]. Refining the recording device Dr Collonge reported a vibration between 32 and $35 \mathrm{~Hz}$. According to Helmotz's experiments, a tetanic contraction appears with a stimulus at $32 \mathrm{~Hz}$ [78]. In the late ' 80 s, phonomyogram was investigated as a competing or alternative technique to EMG [78, 79]. In case of orthostatic tremor, when the subject stands at ease, with a stethoscope we can hear the 14-16 Hz "clicks" of the trembling quadriceps even if the tremor is not visible yet. Permanent muscular contraction, also named "tonic spasticity", is detectable as well. Nevertheless, our experiences showed that phonomyography is less specific, extremely demanding to minimise artefacts and inappropriate during dynamic situations.

\section{CONCLUSION}

Actually kinesiological EMG, either with surface or fine wire electrodes, is still the only means to record objectively muscular patterns and co-ordination between muscles. However, it is a very demanding technique. Recording accurate and reliable signals is not an easy task. Only controlled cross contraction during specific static and/or dynamic movements provoked by experienced individuals can estimate crosstalk versus co-contraction. Force/EMG relationships are complicated because they depend on many technical, anatomical, physiological and mechanical factors. Nowadays EMG cannot measure muscular force accurately. Nevertheless, miniature skin electrodes close to each other, placed on the area of minimal crosstalk make kinesiological EMG the only painless and ambulatory means to assess muscles functions and pattern of muscular activity.

\section{REFERENCES}

[1] TENS (Transcutaneous Electrical Nerve Stimulation) Health article from Healthline ${ }^{\circledR}$ p.1. Available from: http:/www.healthline.com/ natstandardcontent/alt-electroanalgesia [Cited: 12 february 2009]

[2] Basmajian JV. Conscious control of individual motor units. Science 1963; 141: 440-1.

[3] Basmajian JV. Biofeedback: the clinical tool behind the catchword. Mod Med 1976; 44: 60-4.

[4] Basmajian JV. Biofeedback. Principles and practice for clinicians. Baltimore: Williams \& Wilkins 1979.

[5] Aristotle: Parts of animals. Movement of animals. Progression of animals. Transl. by ES Forster. Harvard University Press: Reprint edition 1945.

[6] Baillière JB. Oeuvres anatomiques, physiologiques et médicales de Galien. Paris 1854; pp. 453-454. Transl. by Daremberg Ch. Available from: http://books.google.ch/books?id=CV0OAAAAQA AJ\&printsec $=$ titlepage $\& \mathrm{hl}=\mathrm{fr} \# \mathrm{v}=$ onepage $\& \mathrm{q}=\& \mathrm{f}=$ false $[$ Cited: 12 february 2009]

[7] Sautel N. Michel-Ange. Biographie Paris: Gallimard 2006.

[8] O'Malley C, Saunders CM. Leonardo da Vinci on the human body: The anatomical, physiological and embryological drawings of Leonardo da Vinci. New York: Henry Shuman Press 1952.

[9] Mac Conaill MA, Basmajian JV. Muscles and movements a basis for human kinsiology. Baltimore: Williams \& Wilkins 1969; p. 104-43.

[10] The illustrations from the works of Andreas Vesalius of Brussels. A discussion of the plates and a biographical sketch of Vesalius with annotations and translations. Saunders JB de CM, O’Malley, Eds. Dover Publication. New York 1973. Reprint of the $1^{\text {st }}$ edition published by World Publishing Company Cleveland 1950.

[11] Rasch PJ, Burke RJ. Kinesiology and applied anatomy. The science of human movement. $3^{\text {rd }}$ ed. Philadelphia: Lea \& Febiger 1967. p. 2.

[12] Borelli G. De Motu animalium. Pars 1 \& 2. Angelo Bernabo ed. Rome. 1680-1. Translated from latin by Maquet P. On the movement of animals. Berlin: Springer-Verlag. 1989. Available from: http://gallica.bnf.fr/ark:/12148/bpt6k512312.image.f320.table DesMatieres [Cited: $5^{\text {th }}$ August 2010].

[13] Rasch PJ, Burke RJ. Kinesiology and applied anatomy. The science of human movement. $3^{\text {rd }}$ ed. Philadelphia: Lea \& Febiger 1967. p. 3.

[14] Rasch PJ, Burke RJ. Kinesiology and applied anatomy. The science of human movement. $3^{\text {rd }}$ ed. Philadelphia: Lea \& Febiger 1967. p. 5-6.

[15] Galvani Luigi Biography. Available from: http://corrosion-doctors org/Biographies/GalvaniBio.htm or from: http://www.answers.com/ topic/luigi-galvani [Cited: $7^{\text {th }}$ January 2009 ]

[16] Volta G. Available from: http://en.wikipedia.org/wiki/Luigi_Gal vani [Cited: August $4^{\text {th }} 2010$ ]

[17] Voltaic pile. Available from: http://www.magnet.fsu.edu/education/ tutorials/museum/voltaicpile.html [Cited: August 5 th 2010]

[18] Faraday M. Biography. Available from: http://en.wikipedia.org/ wiki/Michael_Faraday [Cited: February 20 ${ }^{\text {th }}$ 2009] 
[19] Faraday's electrical current and law of induction. Available from: http://en.wikipedia.org/wiki/Faraday\%27s_law_of_induction [Cited: February $20^{\text {th }} 2009$ ]

[20] Duchenne de Boulogne GM. Physiologie des mouvements. Démontrée à l'aide de l'expérimentation électrique et de l'observation clinique et applicable à l'étude des paralysies et des déformations. Paris :Baillière 1867. transl. by Kaplan EB. Physiology of motion. Demonstrated by means of electrical stimulation and clinical observation and applied to the study of paralysis and deformities. Philadelphia : JB Lippincott 1949.

[21] Waters RL, Perry J, Garland D. Surgical correction of gait abnormalities following stroke. Clin Orthop Relat Res 1978; 131: p. 54-63.

[22] Duchenne de Boulogne G.-B. Mécanisme de la physionomie humaine ou analyse électro-physiologique de l'expression des passions. Paris: Baillière $2^{\text {nd }}$ ed. 1876. English translation available from: http://books.google.ch/books

[23] Janssen J. Présentation de quelques spécimens de photographies solaires obtenues avec un appareil construit pour la mission du Japon Comptes rendus hebdomadaires des séances de l'académie des sciences 1874; Tome LXXVIII, $\mathrm{N}^{\circ} 1: 1730-1$.

[24] Marey EJ. La machine animale, locomotion terrestre et aérienne. Paris: Baillière 1882.

[25] Marey EJ. Le vol des oiseaux. Paris: Masson 1890.

[26] Marey EJ. Le Mouvement. Paris: Masson 1894.

[27] Carlet G. Essai expérimental sur la locomotion humaine. Etude de la marche. Ann Sci Nat 1872; XVI: 1-92.

[28] Rasch PJ, Burke RJ. Kinesiology and applied anatomy. The science of human movement $3^{\text {rd }}$ ed. Philadelphia: Lea \& Febiger 1967. p. 4.

[29] Rasch PJ, Burke RJ. Kinesiology and applied anatomy. The science of human movement. $3^{\text {rd }}$ ed. Philadelphia: Lea \& Febiger 1967; p. 9 .

[30] Steinhaus AH. Strength from Morpurgo to Muller. A half century of research. J Ass Phys Ment Rehabil 1955; 9: 147-50.

[31] Siebert WH. Untersuchungen uber hypertrophie des skelet-muskels Zschr Klin Med 1928; 109: 350-9. Transl. by Kramer R. Investigation of hypertrophy of the skeletal muscle. J Ass Phys Ment Rehabil 1960; 14: 153-7.

[32] De Lateur B. Exercise for strength and endurance. In: Basmajian JV, Ed. Therapeutic exercise student edition. $2^{\text {nd }}$ Ed. Baltimore: Williams \& Wilkins 1980; p. 33-8.

[33] Schram DA. Resistance exercise. In: Basmajian JV, Ed. Therapeutic exercise student edition. $2^{\text {nd }}$ ed. Baltimore: Williams $\&$ Wilkins 1980; pp. 98-107.

[34] Amar J. Le moteur humain et les bases du travail professionnel. Paris: Dunod \& Pitat 1914; pp.155-76. on the web: Amar J. The Human Motor Irvington Pub 1972. (Physical Education Reprint Ser).

[35] Amar J. The physiology of industrial organisation and the reemployment of the disabled Transl. Miall B. London Library Press 1918. Available at: http://www.archive.org/stream/physiologyindus 00kentgoog\#page/n6/mode/1up [Cited: $15^{\text {th }}$ february 2009]

[36] Perreault EJ, Heckman CJ, Sandercock TG. Hill muscle model errors during movement are greatest within the physiologically relevant range of motor unit firing. J Biomech 2003; 36: 211-8.

[37] Matteucci C. Phénomène physiologique produit par les muscles en contraction. Ann Chim Phys 1842; VI, 3ème série : 339-41

[38] Matteucci C. Réclamation de priorité à l'occasion des communications récentes de $\mathrm{M}$. Du Bois-Reymond, sur des recherches d'électricité. C R Acad Sci 1850; 30: 479-80.

[39] Du Bois Reymond E. Réponse à la réclamation de priorité de $\mathrm{M}$. Matteucci. C R Acad Sci 1850; 30: 512-5.

[40] Du Bois Reymond E. Seconde réponse à la réclamation de priorité de M. Matteucci. C R Acad Sci 1850; 30: 563-6.

[41] Matteucci C. Réponses aux deux dernières lettres de M. Du Bois Reymond, insérées dans les $\mathrm{n}^{\circ} 17$ et 18 des Comptes rendus de l'Académie, et en général à toutes les observations faites par le même auteur sur quelques unes de mes recherches d'électrophysiologie. C R Acad Sci 1850; 30: 699-708.

[42] Rasch PJ, Burke RJ. Kinesiology and applied anatomy. The science of human movement. $3^{\text {rd }}$ ed. Philadelphia: Lea \& Febiger 1967; p. 22.

[43] Piper H. Uber den willkurlichen Muskeltetanus. Pflügers Gesamte Physiol Menschen. Tiere 1907; 119: 301-38.

[44] Brown P, Salenius S, Rothwell JC, Hari R. Cortical Correlate of the Piper Rhythm in Humans. J Neurophysiol 1998; 80: 2911-7.
[45] Erlander J. Available from: http://www.faqs.org/health/bios/13/Jos eph-Erlanger.htm [Cited: February 15 2010 ] http://nobelprize. org/nobel_prizes/medicine/laureates/1944/erlanger-bio.html [Cited: February $15^{\text {th }} 2010$ ]

[46] Adrian ED. Interpretation of the electromyogram. Lancet 1925; I (lecture 1) : 1229-33.

[47] Adrian ED. Interpretation of the electromyogram. Lancet 1925; I (lecture 2): p. 1282-6.

[48] Beevor CE. Muscular movements and their representation in the central nervous system. Lancet 1903; I: 1715-24.

[49] Scherb, R: Weitere Ergebnisse myokinesigraphischer Untersuchungen. 3. Mitteilung zur Myokinesigraphie. Zeitschr Orthop Chir 1927; 48: 156.

[50] Scherb, R Kinetisch-diagnostische Analyse von Gehstörungen: Technik undResultate der Myokinesigraphie/ von Richard Scherb. Zeitschr Orthop 1952; 82: 31-80.

[51] Basmajian JV. Muscles alive. Their function revealed by electromyography. $2^{\text {nd }}$ ed. Philadelphia: Williams \& Wilkins 1967; pp.21-2.

[52] Basmajian JV, Stecko G.A. A new bipolar indwelling electrode for electromyography. J Appl Physiol 1962; 17: 849.

[53] Eberhart HD, Inmann VT. An evaluation of experimental procedures used in a fundamental study of human locomotion. Ann N Y Acad Sci 1951; 51: 1213-28

[54] Institute of engineering research (US). The pattern of muscular activity in the lower extremity during walking. Prosthetic devices research project. Berkeley: University of California 1953.

[55] Inmann VT, Ralston HJ, Todd F. Human Walking. Baltimore: Williams \& Wilkins 1981.

[56] Close JR. Functional anatomy of the extremities. Some electronic and kinematic methods of study. Springfield, IL: Charles C Thomas Publishers 1973; p.81-2.

[57] Close JR. Motor function in the lower extremity. Analyses by electronic instrumentation. Springfield, IL: Charles C Thomas Publishers 1964

[58] Inmann VT, Ralston H, Todd F. Human walking. Baltimore: William \& Wilkins 1981; pp. 89-93.

[59] Lindström L, Kadefors R, Petersen I. An electromyographic index for localized muscle fatigue. J Appl Physiol 1977; 43: 750-4.

[60] Kadefors R, Lindström L, Petersen I, Ortengren R. EMG in objective evaluation of localized muscle fatigue. Scand J Rehabil Med 1978; 10(suppl 6): 75-94.

[61] De Luca CJ, Gilmore LD, Roy SH. Methodology for measuring muscle fatigue objectively. 37th ACEMB, Los Angeles, Sept. 17$19,1984$.

[62] De Luca CJ. Myoelectric manifestations of localized muscular fatigue in humans. Crit Rev Biomed Eng 1985; 11: 251-79.

[63] Merletti R, Knaflitz M, De Luca CJ. Myoelectric manifestations of fatigue in voluntary and electrically elicited contractions. J Appl Physiol 1990; 69: 1810-20.

[64] Linnamo V, Bottas R, Komi PV. Force and EMG power spectrum during and after eccentric and concentric fatigue. J Electromyogr Kinesiol 2000; 10: 293-300.

[65] Disselhorst-Klug C, Schmitz-Rode T, Rau G. Surface electromyography and muscle force: Limits and new approaches for applications-force relationship. Clin Biomech 2009; 24 : 225 35.

[66] Von Tscharner V. Electromyographic signal analyzed by wavelet transform. Int Soc Biomech XVIIth Congress Book of Abstracts Calgary 8, 1999; p. 482.

[67] Von Tscharner V. Intensity analysis in time-frequency space of surface myoelectric signals by wavelets of specified resolution. J Electromyogr Kinesiol 2000; 10: 433-45.

[68] Göpfert B, Tscharner V, Wirz D, Romkes J. Time frequency analysis of the electromyogram of thigh and shaft in level walking Gait Posture 2002; 16(suppl 2): S155-S156.

[69] Von Tscharner V, Goepfert B. Gender dependent EMGs of runners resolved by time/frequency and principal pattern analysis. J Electromyogr Kinesiol 2003; 13: 253-72.

[70] Valderrabano V, Nigg BM, Hintermann B, et al. Muscular lower leg asymmetry in middle-aged people. Foot Ankle Int 2007; 28: 242-9.

[71] Ivanenko Y P, Poppele R E, Lacquaniti F. Spinal cord maps of spatiotemporal alpha-motoneuron activation in humans walking at different speeds. J Neurophysiol 2006; 95: 602-18. 
[72] Blanc Y. Contribution de l'EMG cinésiologique des muscles péroniers latéraux pour différencier les instabilités chroniques de cheville et le syndrome du sinus du tarse. Thèse de doctorat en réadaptation. Université Catholique de Louvain. Faculté de Médecine. Institut d'éducation physique et de réadaptation. 1994; p. 182 .

[73] Marinacci AA, Horande M. Electromyography in neuromuscular re-education. Bull Los Angeles Neurol Soc 1960; 25: 57-71.

[74] Basmajian JV. Control and training of individual motor units. Science $1963 ; 141: 440-1$

[75] Basmajian JV, Blumenstein R. Electrode placement in EMG biofeedback. Baltimore: Williams \& Wilkins 1980.
[76] Marey EJ. Etudes graphiques sur la nature de la contraction musculaire. Extrait du Journal de l'anatomie éd Robin Paris 1866 1er mars: p.1.

[77] Maton B, Petitjean M, Cnockaert JC. Phonomyogram and electromyogram relationships with isometric force reinvestigated in man. Eur J Appl Physiol 1990; 60: 194-201.

[78] Dalton PA, Stokes MJ. Acoustic myography for investigation human skeletal muscle fatigue. Eur J Appl Physiol 1991; 71: 14226.

[79] Petitjean M, Maton B. Phonomyogram for single motor unit during voluntary isometric contraction. Eur J Appl Physiol 1995; 71: 21522

(C) Blanc and Dimanico; Licensee Bentham Open

This is an open access article licensed under the terms of the Creative Commons Attribution Non-Commercial License (http: //creativecommons.org/licenses/by$\mathrm{nc} / 3.0 /$ ) which permits unrestricted, non-commercial use, distribution and reproduction in any medium, provided the work is properly cited. 